\title{
RESEARCH
}

\section{Hospital volume and patient outcomes in pulmonary embolism}

\author{
Drahomir Aujesky MD MSc, Maria K. Mor PhD, Ming Geng MS, Michael J. Fine MD MSc, \\ Bertrand Renaud MD, Said A. Ibrahim MD MPH
}

$\infty$

See related article page 58

\section{ABSTRACT}

Background: In numerous high-risk medical and surgical conditions, a greater volume of patients undergoing treatment in a given setting or facility is associated with better survival. For patients with pulmonary embolism, the relation between the number of patients treated in a hospital (volume) and patient outcome is unknown.

Methods: We studied discharge records from 186 acute care hospitals in Pennsylvania for a total of 15531 patients for whom the primary diagnosis was pulmonary embolism. The study outcomes were all-cause mortality in hospital and within 30 days after presentation for pulmonary embolism and the length of hospital stay. We used logistic models to study the association between hospital volume and 30-day mortality and discrete survival models to study the association between in-hospital mortality and time to hospital discharge.

Results: The median annual hospital volume for pulmonary embolism was 20 patients (interquartile range $10-42$ ). Overall in-hospital mortality was $6.0 \%$, whereas 30 -day mortality was $9.3 \%$. In multivariable analysis, very-highvolume hospitals ( $\geq 42$ cases per year) had a significantly lower odds of in-hospital death (odds ratio [OR] 0.71, 95\% confidence interval $[\mathrm{Cl}] 0.51-0.99$ ) and of 30-day death (OR $0.71,95 \% \mathrm{Cl} 0.54-0.92$ ) than very-low-volume hospitals ( $<10$ cases per year). Although patients in the veryhigh-volume hospitals had a slightly longer length of stay than those in the very-low-volume hospitals (mean difference 0.7 days), there was no association between volume and length of stay.

Interpretation: In hospitals with a high volume of cases, pulmonary embolism was associated with lower short-term mortality. Further research is required to determine the causes of the relation between volume and outcome for patients with pulmonary embolism.

Une version française de ce résumé est disponible à l'adresse www.cmaj.ca/cgi/content/full/I78/I/27/DCI

CMAJ 2008;178(I):27-33
7 he association between the number of patients treated in a hospital (volume) and patient outcomes is well established for various high-risk surgical and medical conditions. ${ }^{1}$ Prior studies have demonstrated that higher patient volume is associated with lower mortality among patients who have undergone certain cardiovascular procedures and certain types of cancer surgery. ${ }^{2}$ Although less extensively documented, the outcomes of several conditions not requiring surgery, such as acute myocardial infarction and AIDS, and of certain nonsurgical interventions, such as mechanical ventilation, may also be related to the volume of patients treated. ${ }^{1,3,4}$ Potential reasons for the relation between patient volume and outcome include greater provider experience and selective referral to providers with better outcomes. ${ }^{5}$

Acute pulmonary embolism is a major health problem, with an estimated incidence in the United States of 23-69 cases per 100 ooo population annually.,7 Short-term mortality related to pulmonary embolism has been estimated at II $\%,{ }^{8}$ rising to $25 \%$ among patients with cardiogenic shock. ${ }^{9}$ The diagnosis of this condition requires sophisticated radiographic procedures such as spiral computed tomography, ventilation-perfusion lung scanning, pulmonary angiography and venous ultrasonography. ${ }^{10}$ In addition, the quality of anticoagulant therapy, the mainstay of treatment for this condition, may depend on provider experience and the availability of specialized anticoagulation clinics. ${ }^{11}$ Access to thrombolysis and other measures of intensive care may also vary. Consequently, it is likely that an association exists between hospital case volume and outcome for patients with pulmonary embolism. We sought to assess whether hospitals that care for large numbers of patients with pulmonary embolism have lower short-term mortality than those caring for low numbers of such patients and whether hospital volume is associated with length of hospital stay.

From the Division of Internal Medicine (Aujesky), University of Lausanne, Lausanne, Switzerland; the VA Center for Health Equity Research and Promotion (Mor, Geng, Fine, Ibrahim), Pittsburgh, Pa.; the Department of Biostatistics, Graduate School of Public Health (Mor, Geng) and the Division of General Internal Medicine, Department of Medicine (Fine, Ibrahim), University of Pittsburgh, Pittsburgh, Pa.; and the Department of Emergency Medicine (Renaud), University Hospital Henri Mondor, Paris, France 


\section{Methods}

\section{Patient identification and eligibility}

We used the Pennsylvania Health Care Cost Containment Council database to identify patients discharged from Pennsylvania hospitals between Jan. I, 2000, and Nov. 30, 2002, with a diagnosis of pulmonary embolism. This database contains information on demographic characteristics, insurance status, hospital region and number of beds, diagnosis and procedure codes (according to the International Classification of Diseases, 9th revision, Clinical Modification), and length of stay for patients discharged from all I86 nongovernmental acute care hospitals (i.e., hospitals other than those operated by the Veterans Administration) in Pennsylvania.

We included inpatients I8 years of age or older who were discharged with a primary diagnosis of pulmonary embolism on the basis of the following International Classification of Diseases codes: 4I5.I, 4I5.II, 4I5.I9 and 673.20-673.24. To ensure that we identified the most severely ill patients for whom pulmonary embolism was the primary reason for hospital admission, we also included inpatients with a secondary diagnosis code for pulmonary embolism and one of the following primary codes that may represent complications or treatments of this condition: respiratory failure (518.8I), cardiogenic shock (785.5I), cardiac arrest (427.5), secondary pulmonary hypertension (4I6.8), syncope (780.2), thrombolysis (99.10), and intubation or mechanical ventilation ( 96.04 , $96.05,96.70-96.72$ ).

We excluded patients who had a secondary diagnosis code for pulmonary embolism without a primary code representing a complication or treatment of this condition and those who had been transferred from another health care facility, because we believe that such patients are more likely to have had pulmonary embolism as a complication of the hospital stay. We excluded follow-up records for patients who were subsequently transferred to other hospitals. We also excluded patients without the identifiers required for linkage to the necessary clinical data, and those for whom mortality information was not available. The Institutional Review Board at the University of Pittsburgh approved this study.

\section{Patient and hospital characteristics}

We abstracted patients' demographic characteristics and insurance status as well as hospital region, number of beds per site and annual number of pulmonary embolism cases for each site from the Pennsylvania Health Care Cost Containment Council database. Hospital teaching status was ascertained from the Council of Teaching Hospitals and Health Systems of the Association of American Medical Colleges. We obtained baseline clinical variables by linking records for eligible patients to the Atlas Database (MediQual, Marlborough, Massachusetts), which includes clinical findings at presentation for all inpatients treated at nongovernmental acute care hospitals in Pennsylvania. Severity of illness was quantified using the pulmonary embolism severity index, a prognostic model for patients with pulmonary embolism that was developed and validated using these data from the Pennsylvania Health Care Cost Containment Council and Atlas data- bases. ${ }^{12,13}$ On the basis of the severity index, each patient was classified into I of 5 classes (I to V) of increasing risk of 30day mortality. ${ }^{12}$ To ascertain whether patients received thrombolysis, we used International Classification of Diseases procedure codes (99.I0) from the Pennsylvania Health Care Cost Containment Council and Atlas databases.

\section{Study outcomes}

The study outcomes were all-cause mortality in hospital and within 30 days after presentation and the length of hospital stay. We obtained mortality data by linking patient records to the National Death Index using unique patient identifiers, including social security number, name, date of birth and sex. ${ }^{14-16}$ The National Death Index has a sensitivity and specificity of over $97 \%$ for mortality. ${ }^{16}$ Because the databases were linked by staff from the Pennsylvania Health Care Cost Containment Council, we had no access to personal patient identifiers. We abstracted length of stay from the Pennsylvania Health Care Cost Containment Council database.

\section{Statistical analyses}

We defined hospital volume as the mean number of discharges for patients with pulmonary embolism per year during the study period. We performed $\chi^{2}$ tests for categorical variables and nonparametric Kruskal-Wallis tests for continuous variables to compare hospital and patient characteristics across the 4 groups of hospital volume. Nonparametric tests were used for the continuous variables because of the skewed distribution of these variables. We used logistic regression analysis to examine the association between hospital volume and mortality within 30 days after presentation and a discrete survival approach to examine the association with in-hospital mortality. Data for surviving patients were censored at 30 days. To account for the effects of clustering of patients within hospitals, we used generalized estimating equations. ${ }^{17}$ We controlled for hospital region within Pennsylvania, hospital teaching status, race, insurance status, severity of illness according to the pulmonary embolism severity index (which incorporates age, sex, history of cancer, history of chronic lung disease, history of heart failure, systolic arterial blood pressure $<$ Ioo $\mathrm{mm} \mathrm{Hg}$, pulse $\geq$ IIo beats $/ \mathrm{min}$, respiratory rate $\geq 30$ breaths $/ \mathrm{min}$, body temperature $<36^{\circ} \mathrm{C}$, arterial oxygen saturation $<90 \%$ and altered mental status) and administration of thrombolytic therapy. Because there is no accepted definition of low versus higher hospital volumes for pulmonary embolism, we modelled annual volume as a categorical variable defined by 4 equal groups across all hospitals, a commonly used approach in volume-outcome studies.,18-20 In our study, these hospital groups were defined as follows: very low volume, < Io cases per year; low volume, I0-19 cases per year; high volume, 20-4I cases per year; and very high volume, $\geq 42$ cases per year).

We used the same discrete survival approach to examine the association between hospital volume and time to discharge, adjusting for previously described hospital and patient factors. A lower odds of discharge corresponds to a longer length of stay. Data for patients who died in hospital were censored at the time of death. 


\section{Results}

From the 17733 patient discharges that met our general inclusion criteria (diagnosis code for pulmonary embolism), I5 53I constituted the final study cohort after application of specific exclusion criteria and removal of records with missing clinical and mortality data (Figure I). The study hospitals were diverse in terms of geographic region, teaching status and number of beds (Table I). Almost half of the study hospitals $(87[47 \%])$ were located in urban areas (Pittsburgh, Philadelphia and their surrounding areas). Overall, 25 (I3\%) of the hospitals were teaching hospitals. The median annual volume was 20 patients with pulmonary embolism (interquartile range Io-42). Very-high-volume hospitals $(\geq 42$ cases per year) were more likely than very-low-volume hospitals ( $<$ Io cases per year) to be teaching hospitals ( $37 \% \mathrm{v} .2 \%$ ) and to have more hospital beds (402 v. 97). Overall, there were 667 patients $(4.3 \%)$ in the very-low-volume hospitals, 1907 (I2.3\%) in the low-volume hospitals (IO-I9 cases per year), $4222(27.2 \%)$ in the high-volume hospitals (20-4I cases per year) and $8735(56.2 \%)$ in the very-high-volume hospitals (Table 2). Patients in very-high-volume hospitals were more likely than those in very-low-volume hospitals to be black (I2.8\% v. $6.7 \%$ ) and to have private health insurance $(38.8 \%$ v. 3 I. $9 \%)$. The percentages of the most severely ill pa-

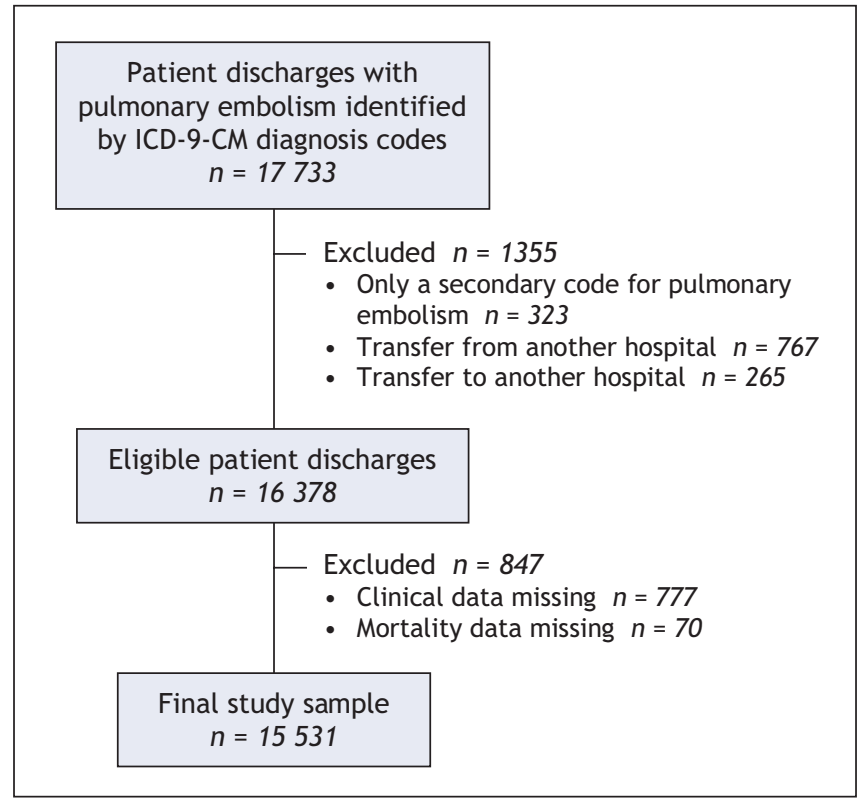

Figure 1: Identification of sample for study of outcomes of pulmonary embolism in relation to hospital case volume. ICD-9-

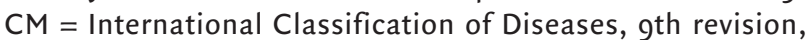
Clinical Modification.

Table 1: Characteristics of 186 acute care hospitals in Pennsylvania by volume of pulmonary embolism cases

\begin{tabular}{|c|c|c|c|c|c|c|}
\hline \multirow[b]{2}{*}{ Characteristic } & \multicolumn{5}{|c|}{ Hospital volume*; no. (\%) of hospitals $\dagger$} & \multirow[b]{2}{*}{$p$ value } \\
\hline & Overall & $\begin{array}{c}\text { Very low } \\
(<10 \text { cases } / y r)\end{array}$ & $\begin{array}{c}\text { Low } \\
(10-19 \text { cases/yr) }\end{array}$ & $\begin{array}{c}\text { High } \\
(20-41 \text { cases } / y r)\end{array}$ & $\begin{array}{c}\text { Very high } \\
(\geq 42 \text { cases } / y r)\end{array}$ & \\
\hline Total no. & $186(100)$ & $46(100)$ & $47(100)$ & $47(100)$ & $46(100)$ & - \\
\hline Region & & & & & & 0.48 \\
\hline $\begin{array}{l}\text { Pittsburgh and } \\
\text { surrounding area }\end{array}$ & $39 \quad(21)$ & $11(24)$ & 8 (17) & $6(13)$ & $14(30)$ & - \\
\hline $\begin{array}{l}\text { Northwest } \\
\text { Pennsylvania }\end{array}$ & $24 \quad(13)$ & 8 (17) & 8 (17) & 7 (15) & $1 \quad(2)$ & - \\
\hline $\begin{array}{l}\text { Southern Laurel } \\
\text { Highlands }\end{array}$ & $12 \quad(6)$ & $4 \quad(9)$ & $4 \quad(9)$ & 2 (4) & $2 \quad(4)$ & - \\
\hline $\begin{array}{l}\text { North Central } \\
\text { Pennsylvania }\end{array}$ & $14 \quad(8)$ & 5 (11) & $316)$ & $316)$ & 3 (7) & - \\
\hline $\begin{array}{l}\text { South Central } \\
\text { Pennsylvania }\end{array}$ & $18 \quad(10)$ & $3 \quad(7)$ & $3 \quad(6)$ & $5(11)$ & 7 (15) & - \\
\hline $\begin{array}{l}\text { Northeast } \\
\text { Pennsylvania }\end{array}$ & $18 \quad(10)$ & $6 \quad(13)$ & 5 (11) & 5 (11) & (4) & - \\
\hline $\begin{array}{l}\text { Eastern } \\
\text { Pennsylvania }\end{array}$ & $13 \quad(7)$ & 2 (4) & $4 \quad(9)$ & $4 \quad(9)$ & $3 \quad(7)$ & - \\
\hline Philadelphia & $23 \quad(12)$ & $6 \quad(13)$ & $4 \quad(9)$ & $7 \quad(15)$ & $6 \quad(13)$ & - \\
\hline $\begin{array}{l}\text { Area surrounding } \\
\text { Philadelphia }\end{array}$ & $25 \quad(13)$ & $1 \quad(2)$ & 8 (17) & $8 \quad(17)$ & $8 \quad(17)$ & - \\
\hline $\begin{array}{l}\text { No. of beds, median } \\
\text { (interquartile range) }\end{array}$ & $192(106,302)$ & $97(49,146)$ & $137(100,188)$ & $239(180,318)$ & $402(255,566)$ & $<0.001$ \\
\hline Teaching hospital & $25 \quad(13)$ & $1 \quad(2)$ & $3 \quad(6)$ & $4 \quad(9)$ & $17 \quad(37)$ & $<0.001$ \\
\hline
\end{tabular}

${ }^{*}$ Hospitals are divided into 4 groups on the basis of hospital volume, where hospital volume is the annual number of cases of pulmonary embolism treated. †Unless stated otherwise. Percentages may not sum to 100 because of rounding. 
tients (severity index risk classes IV and V) in the very-lowvolume hospitals and very-high-volume were similar $(37.5 \%$ v. $36.3 \%, p=0.53)$. Overall in-hospital mortality was $6.0 \%$, whereas 30 -day mortality was $9.3 \%$. The median length of stay was 6 days (interquartile range $4-8$ ).
The unadjusted odds of in-hospital mortality varied significantly by hospital volume $(p=0.03$ ) (Figure 2, online Appendix I [www.cmaj.ca/cgi/content/full/178/I/27/DC2]). In particular, relative to the very-low-volume hospitals, the lowvolume hospitals had significantly lower (by $4 \mathrm{I} \%$ ) unadjusted

Table 2: Characteristics of 15531 patients with pulmonary embolism and their outcomes by hospital volume

\begin{tabular}{|c|c|c|c|c|c|c|}
\hline Characteristic & \multicolumn{5}{|c|}{ Hospital volume*; no. (\%) of patients } & $p$ value \\
\hline Total no. & $15531(100.0)$ & $667(100.0)$ & $1907(100.0)$ & $4222(100.0)$ & $8735(100.0)$ & - \\
\hline \multicolumn{7}{|l|}{ Demographic characteristic } \\
\hline Age, yr & $67(52-77)$ & $67(51-78)$ & $67(51-77)$ & 70 (54-79) & $66(51-76)$ & $<0.001$ \\
\hline \multicolumn{2}{|l|}{ Race } & & & & & $<0.001$ \\
\hline White & $12554(80.8)$ & $580 \quad(87.0)$ & $1660 \quad(87.0)$ & 3417 (80.9) & 6897 (79.0) & - \\
\hline Black & 1701 (11.0) & $45 \quad(6.7)$ & $(5.5)$ & $432 \quad(10.2)$ & 1120 & - \\
\hline Other or unknown & $1276 \quad(8.2)$ & $42 \quad(6.3)$ & $(7.5)$ & $(8.8)$ & $718 \quad(8.2)$ & - \\
\hline \multicolumn{2}{|l|}{ Insurance status } & & & & & $<0.001$ \\
\hline None or unknown & $237 \quad(1.5)$ & $14 \quad(2.1)$ & $(2.8)$ & $(1.4)$ & $(1.2)$ & - \\
\hline \multicolumn{7}{|l|}{ Comorbid disease } \\
\hline History of cancer & 3046 (19.6) & $100(15.0)$ & $330 \quad(17.3)$ & 791 (18.7) & 1825 (20.9) & $<0.001$ \\
\hline Chronic lung disease & 2868 (18.5) & 153 (22.9) & $(20.7)$ & $845 \quad(20.0)$ & 1476 (16.9) & $<0.001$ \\
\hline Heart failure & $2459(15.8)$ & 128 (19.2) & $321 \quad(16.8)$ & 756 (17.9) & 1254 (14.4) & $<0.001$ \\
\hline \multicolumn{7}{|l|}{$\begin{array}{l}\text { Findings of physical } \\
\text { examination }\end{array}$} \\
\hline Pulse $\geq 110$ beats $/ \mathrm{min}$ & 2742 & 119 (17.8) & $327 \quad(17.1)$ & $726 \quad(17.2)$ & 1570 (18.0) & 0.67 \\
\hline $\begin{array}{l}\text { Systolic blood pressure } \\
<100 \mathrm{~mm} \mathrm{Hg}\end{array}$ & 1624 (10.5) & $69(10.3)$ & $(9.9)$ & $423 \quad(10.0)$ & $943(10.8)$ & 0.47 \\
\hline Class I & 3027 (19.5) & $136 \quad(20.4)$ & $378 \quad(19.8)$ & $720 \quad(17.1)$ & 1793 (20.5) & - \\
\hline Class II & 3322 (21.4) & 129 (19.3) & $403 \quad(21.1)$ & $875 \quad(20.7)$ & 1915 (21.9) & - \\
\hline Class III & 3389 (21.8) & 152 (22.8) & $(21.2)$ & $975 \quad(23.1)$ & 1858 & - \\
\hline Class IV & $2512(16.2)$ & 93 (13.9) & $(16.8)$ & $706 \quad(16.7)$ & 1393 (15.9) & - \\
\hline Class V & 3281 (21.1) & $157 \quad(23.5)$ & $402 \quad(21.1)$ & $946 \quad(22.4)$ & 1776 & - \\
\hline Thrombolysis & $356 \quad(2.3)$ & $14 \quad(2.1)$ & $(3.6)$ & $(2.1)$ & $(2.1)$ & 0.001 \\
\hline $\begin{array}{l}\text { Length of stay, } d \text {, median } \\
\text { (interquartile range) }\end{array}$ & $6(4-8)$ & $5(4-8)$ & $6(4-8)$ & $6(4-8)$ & $6(4-8)$ & 0.01 \\
\hline In-hospital mortality & $926 \quad(6.0)$ & $49 \quad(7.3)$ & $(4.6)$ & $(6.4)$ & $(6.0)$ & 0.02 \\
\hline 30-day mortality & 1439 & 78 (11.7) & $(8.3)$ & $(9.7)$ & $(9.1)$ & 0.045 \\
\hline
\end{tabular}

*Hospitals are divided into 4 groups on the basis of hospital volume, where hospital volume is the annual number of cases of pulmonary embolism treated. tUnless stated otherwise. Percentages may not sum to 100 because of rounding.

‡Defined as disorientation, lethargy, stupor or coma.

§With or without supplemental oxygen. 
odds of in-hospital mortality $(p=0.005)$. After adjustment for hospital region, hospital teaching status, race, insurance status, severity of illness (according to the pulmonary embolism severity index) and administration of thrombolytic therapy, differences among the 4 hospital groups remained statistically significant $(p=0.03)$. In particular, the lowvolume hospitals had a significantly lower adjusted odds of in-hospital mortality relative to the very-low-volume hospitals (by $4 \mathrm{I} \%, p=0.006$ ) and the very-high-volume hospitals (by $29 \%, p=0.04)$. The adjusted odds of in-hospital death across the 3 groups of higher-volume hospitals (i.e., the lowvolume, high-volume and very-high-volume hospitals) were not significantly different, except that the low-volume hospitals had a lower odds of in-hospital death relative to the high- volume hospitals (by 23\%, $p=0.036$ ) (data not shown).

There was no significant difference in the unadjusted odds of 30-day mortality by hospital volume $(p=0.10)$, although the low-volume hospitals and the very-high-volume hospitals tended toward lower odds than the very-low-volume hospitals (Figure 3, online Appendix I [www.cmaj.ca/cgi/content/full /I78/I/27/DC2]). After adjustment, the odds of 30-day mortality were significantly lower at the hospitals with higher volumes than at the very-low-volume hospitals $(p=0.049)$, by $33 \%$ at the low-volume hospitals $(p=0.009)$, by $25 \%$ at the high-volume hospitals $(p=0.04)$ and by $29 \%$ at the veryhigh-volume hospitals $(p=0.0 \mathrm{I})$. The adjusted odds of $30-$ day mortality across the 3 groups of hospitals with higher volumes were not significantly different.

\begin{tabular}{lll}
\multicolumn{2}{l}{$\begin{array}{l}\text { Hospital volume } \\
\text { Low }\end{array}$} & OR $(95 \% \mathrm{Cl})$ \\
$(10-19$ cases/yr $)$ & Unadjusted $0.59(0.40-0.85)$ \\
& Adjusted & $0.59(0.41-0.86)$ \\
High & Unadjusted & $0.78(0.55-1.10)$ \\
$(20-41$ cases/yr $)$ & Adjusted & $0.77(0.55-1.07)$ \\
& & \\
Very high & Unadjusted & $0.73(0.52-1.01)$ \\
$(\geq 42$ cases $/ y r)$ & Adjusted & $0.71(0.51-0.99)$
\end{tabular}

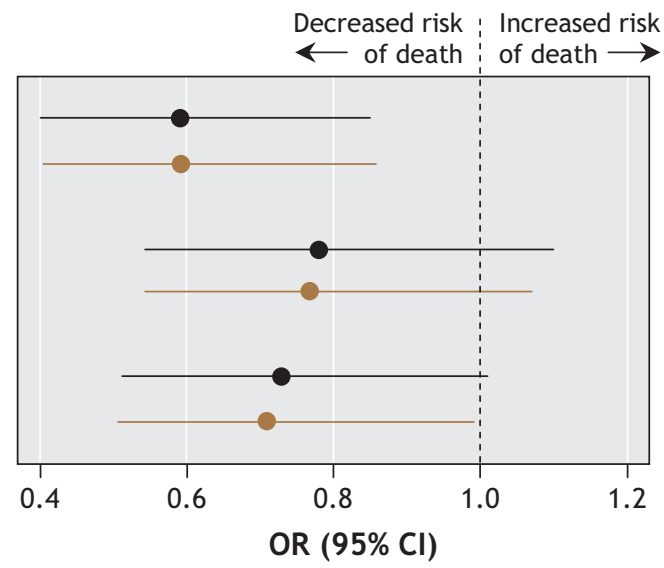

Figure 2: Unadjusted and adjusted odds ratios for in-hospital mortality among 15531 patients with pulmonary embolism, by hospital volume (annual number of cases of pulmonary embolism treated). (Adjustments were for hospital region within Pennsylvania, hospital teaching status, race, insurance status, severity of illness and administration of thrombolytic therapy.) $O R=$ odds ratio, $\mathrm{Cl}=$ confidence interval.

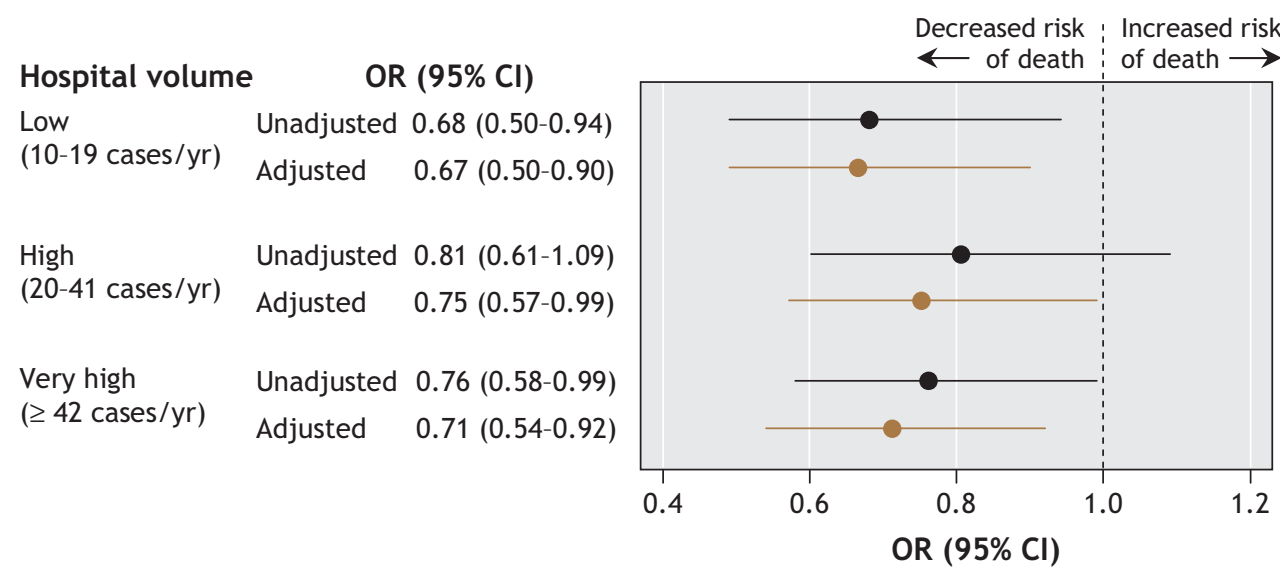

Figure 3: Unadjusted and adjusted odds ratios for 30-day mortality among 15531 patients with pulmonary embolism, by hospital volume (annual number of cases of pulmonary embolism treated). (Adjustments were for hospital region within Pennsylvania, hospital teaching status, race, insurance status, severity of illness and administration of thrombolytic therapy.) OR = odds ratio, $\mathrm{Cl}=$ confidence interval. 
Patients in the very-high-volume hospitals had a slightly longer length of stay than those at the very-low-volume hospitals (mean difference 0.7 days). However, there was no association between volume and length of stay. The unadjusted and adjusted odds of discharge on a given day were not significantly different at hospitals with higher volumes relative to the very-low-volume hospitals (Appendix I, available online at www.cmaj.ca/cgi/content/full/I78/I/27/DC2).

\section{Interpretation}

After adjusting for potential hospital- and patient-related confounders, we found that the hospitals with higher annual volumes of pulmonary embolism cases had significantly lower in-hospital and 30-day mortality than the very-lowvolume hospitals. In addition, there was no significant association between volume and length of stay. Extrapolating from our data, we estimate that, each year, about 5200 patients with pulmonary embolism are managed in hospitals that treat fewer than Io cases per year in the United States. ${ }^{21}$

Although we did not observe a classic dose-response relation between hospital volume and mortality, we found that mortality was lower in hospitals with a volume of at least Io cases per year. There are several possible reasons for the lower mortality in higher-volume hospitals. Physicians at higher-volume hospitals may be more experienced and may better adhere to processes of care with a favourable impact on patient outcomes. Among others, such processes of care include earlier diagnosis of pulmonary embolism through the use of validated diagnostic algorithms ${ }^{10}$ and an overlap of heparin and warfarin therapy of 4 days or more before heparin is stopped..$^{22}$ Moreover, higher-volume hospitals may be better staffed and may have greater availability of system-level factors with potential favourable impact on anticoagulation quality and outcomes. These factors may include the management of anticoagulation through specialized anticoagulation clinics $^{11}$ and the availability of intensive care units to monitor clinically unstable patients. The relative contributions of these possible explanations to lower mortality in highervolume hospitals are not known. Further research is warranted on the associations between physician- and systemlevel factors, processes of care and outcomes for patients with pulmonary embolism.

Although the mechanisms contributing to the lower mortality in higher-volume hospitals remain to be elucidated, our findings have potential implications for improving the quality of care for patients with pulmonary embolism. For example, shifting the care of more patients with this condition to higher-volume hospitals might result in a decrease in the number of deaths related to pulmonary embolism. ${ }^{23}$ However, a shift of care to higher-volume hospitals is justifiable only if it does not delay the diagnosis and treatment of pulmonary embolism (e.g., through longer transportation time to the hospital).

Although unique in the context of pulmonary embolism, our exploration of the volume-outcome relation for patients with an acute medical condition is not new. Although some prior studies showed lower mortality at high-volume hospi- tals for a variety of conditions such as acute myocardial infarction and medical intensive care treatment, ${ }^{3,24}$ others did not find such an association for other common acute medical diseases such as pneumonia and stroke..$^{20,25}$

Our study has several strengths. First, our sample consisted of I5 53I patients from all I 86 nongovernmental acute care hospitals in Pennsylvania, encompassing a wide range of both academic and nonacademic and both urban and rural hospitals. Patients in our sample had a broad spectrum of disease severity, from nonmassive pulmonary embolism to massive pulmonary embolism with cardiopulmonary instability. Second, in contrast to many volume-outcome studies, which have used administrative data only (the estimated relation potentially reflecting unmeasured differences in the severity of illness of patients admitted to low-volume versus higher-volume hospitals ${ }^{26}$ ), our analysis was based on clinical data, and we adjusted for differences in severity of illness using a validated prognostic model for pulmonary embolism. ${ }^{12,13}$ Third, because conventional regression models may overestimate the statistical significance of volume-outcome associations,${ }^{27}$ we accounted for clustering within sites by using a generalized equation estimation approach, which made overestimation of the volume-outcome relation less likely.

Our study also had several limitations. First, patients in our sample were identified using International Classification of Diseases codes for pulmonary embolism rather than standardized radiographic criteria, and patient eligibility may therefore be subject to study selection biases due to hospital coding procedures. In prior studies, up to $96 \%$ of patients with specific codes for pulmonary embolism had objectively documented disease on the basis of chart review criteria, ${ }^{28-30}$ but little is known about the sensitivity of these codes for detecting this condition. In one previous study, the International Classification of Diseases codes missed $13 \%$ of patients with pulmonary embolism. ${ }^{31}$ Thus, we cannot entirely exclude the possibility that the potential for variation in the sensitivity of coding across study centres represents a threat to the validity of our findings (misclassification bias). We also acknowledge that we had no information on the accuracy of the procedure code for thrombolysis (99.Io). Second, we could not assess whether differences in the duration of complaints, timeliness of diagnosis or anticoagulation-related processes of care would explain differences in outcomes between low-volume and higher-volume hospitals. Moreover, we had no information on physician-level (e.g., experience, specialty training and annual volume of pulmonary embolism cases per physician) and system-level (e.g., hospital proximity, staff volume and availability of specialized anticoagulation clinics and intensive care units) factors with a potential impact on the quality of management and outcomes of pulmonary embolism. Thus, we cannot exclude the possibility that the observed lower mortality in higher-volume hospitals was due to unmeasured confounding by these factors. Third, the higher mortality in low-volume hospitals may be due to better detection of deaths related to pulmonary embolism. Although we are not aware of any study demonstrating more accurate mortality assessment in low-volume hospitals, we cannot exclude the possibility that the observed mortality 
difference was due to detection bias. Finally, our analysis cannot determine the direction of the association. ${ }^{4}$ Instead of higher-volume hospitals providing better outcomes, these hospitals may attract more patients on the basis of superior care. However, because pulmonary embolism necessitates emergency care, selected referral to higher-quality providers may play a less important role than would be the case for elective procedures.

In conclusion, our results suggest that, in hospitals with a higher case volume, pulmonary embolism is associated with lower short-term mortality. Further research is required to determine the causes of the relation between volume and outcome for patients with pulmonary embolism.

This article has been peer reviewed.

Competing interests: None declared.

Contributors: Each author contributed substantially to the conception and design of the study and the analysis or interpretation of the data, helped in drafting the article or revised it critically for important intellectual content, and gave final approval of the version to be published.

Acknowledgements: This study was funded by grant I R2I HLo7552I-oIAI from the National Heart, Lung, and Blood Institute, Bethesda, Maryland. Michael Fine is a recipient of a $\mathrm{K}_{24}$ career development award from the National Institute of Allergy and Infectious Diseases, Bethesda, Maryland. Said Ibrahim is a recipient of a career development award from the VA Health Services Research and Development Office and the Robert Wood Johnson Foundation's Harold Amos Faculty Development Award.

\section{REFERENCES}

I. Halm EA, Lee C, Chassin MR. Is volume related to outcome in health care? A systematic review and methodologic critique of the literature. Ann Intern Med 2002; I37:5II-20.

2. Birkmeyer JD, Siewers AE, Finlayson EV, et al. Hospital volume and surgical mortality in the United States. N Engl J Med 2002;346:II28-37.

3. Thiemann DR, Coresh J, Oetgen WJ, et al. The association between hospital volume and survival after acute myocardial infarction in elderly patients. $N$ Engl J Med I999;340:I640-8.

4. Kahn JM, Goss CH, Heagerty PJ, et al. Hospital volume and the outcomes of mechanical ventilation. N Engl J Med 2006;355:4I-50.

5. Luft HS, Hunt SS, Maerki SC. The volume-outcome relationship: Practice-makesperfect or selective-referral patterns? Health Serv Res 1987;22:157-82.

6. Anderson FA Jr, Wheeler HB, Goldberg RJ, et al. A population-based perspective of the hospital incidence and case-fatality rates of deep vein thrombosis and pulmonary embolism. The Worcester DVT Study. Arch Intern Med I991;I5I:933-8.

7. Silverstein MD, Heit JA, Mohr DN, et al. Trends in the incidence of deep vein thrombosis and pulmonary embolism: a 25-year population-based study. Arch Intern Med i 998 ; I5 8:585-93.

8. Goldhaber SZ, Visani L, De Rosa M. Acute pulmonary embolism: clinical outcomes in the International Cooperative Pulmonary Embolism Registry (ICOPER). Lancet I999;353:1386-9.
9. Kasper W, Konstantinides S, Geibel A, et al. Management strategies and determinants of outcome in acute major pulmonary embolism: results of a multicenter registry. J Am Coll Cardiol 1997;30:1165-71.

Io. Roy PM, Meyer G, Vielle B, et al. Appropriateness of diagnostic management and outcomes of suspected pulmonary embolism. Ann Intern Med 2006;I44:I57-64.

II. Chiquette E, Amato MG, Bussey HI. Comparison of an anticoagulation clinic with usual medical care: anticoagulation control, patient outcomes, and health care costs. Arch Intern Med I998; I58:I64I-7.

I2. Aujesky D, Obrosky DS, Stone RA, et al. Derivation and validation of a prognostic model for pulmonary embolism. Am J Respir Crit Care Med 2005;172:104I-6.

I3. Aujesky D, Roy PM, Le Manach CP, et al. Validation of a model to predict adverse outcomes in patients with pulmonary embolism. Eur Heart J 2006;27:476-8I.

I4. MacMahon B. The National Death Index. Am J Public Health I983;73:1247-8.

I5. Williams BC, Demitrack LB, Fries BE. The accuracy of the National Death Index when personal identifiers other than Social Security number are used. Am J Public Health $1992 ; 82: 1145-7$.

I6. Cowper DC, Kubal JD, Maynard C, et al. A primer and comparative review of major US mortality databases. Ann Epidemiol 2002;12:462-8.

I7. Zeger SL, Liang KY. Longitudinal data analysis for discrete and continuous outcomes. Biometrics I986;42:12I-30.

I8. Tu JV, Austin PC, Chan BT. Relationship between annual volume of patients treated by admitting physician and mortality after acute myocardial infarction. JAMA 200I;285:3116-22.

I9. Bardach NS, Zhao S, Gress DR, et al. Association between subarachnoid hemorrhage outcomes and number of cases treated at California hospitals. Stroke 2002;33:I85I-6.

20. Lindenauer PK, Behal R, Murray CK, et al. Volume, quality of care, and outcome in pneumonia. Ann Intern Med 2006; I44:262-9.

2I. Kozak LJ, DeFrances CJ, Hall MJ. National Hospital Discharge Survey: 2004 annual summary with detailed diagnosis and procedure data. National Center for Health Statistics. Vital Health Stat 2006;13:64

22. Aujesky D, Long JA, Fine MJ, et al. African American race was associated with an increased risk of complications following venous thromboembolism. J Clin Epidemiol 2007;60:410-6.

23. Dudley RA, Johansen KL, Brand R, et al. Selective referral to high-volume hospitals: estimating potentially avoidable deaths. JAMA 2000;283:1159-66.

24. Durairaj L, Torner JC, Chrischilles EA, et al. Hospital volume-outcome relationships among medical admissions to ICUs. Chest 2005;128:I682-9.

25. Bateman BT, Schumacher HC, Boden-Albala B, et al. Factors associated with inhospital mortality after administration of thrombolysis in acute ischemic stroke patients: an analysis of the nationwide inpatient sample 1999 to 2002. Stroke 2006;37: $440-6$.

26. Tsai AC, Votruba M, Bridges JF, et al. Overcoming bias in estimating the volumeoutcome relationship. Health Serv Res 2006;41:252-64.

27. Urbach DR, Austin PC. Conventional models overestimate the statistical significance of volume-outcome associations, compared with multilevel models. J Clin Epidemiol 2005;58:39I-400.

28. Murin S, Romano PS, White RH. Comparison of outcomes after hospitalization for deep venous thrombosis or pulmonary embolism. Thromb Haemost 2002;88:407-I4

29. White RH, Gettner S, Newman JM, et al. Predictors of rehospitalization for symptomatic venous thromboembolism after total hip arthroplasty. N Engl J Med 2000; 343:1758-64.

30. White RH, Romano PS, Zhou H, et al. Incidence and time course of thromboembolic outcomes following total hip or knee arthroplasty. Arch Intern Med I998; I58: I525-3I.

31. Proctor MC, Greenfield LJ. Pulmonary embolism: diagnosis, incidence and implications. Cardiovasc Surg 1997;5:77-8I.

Correspondence to: Dr. Drahomir Aujesky, Service de Médecine Interne, BH 10-622, Centre Hospitalier, Universitaire Vaudois, IOII Lausanne, Switzerland; fax +4I 2I 3I4 087I;

drahomir.aujesky@chuv.ch 